DOI: 10.21315/aos2021.16.2.2

ARTICLE INFO

Submitted: 02/09/2020

Accepted: 17/06/2021

Online: 22/12/2021

\section{The Relationship of Dental Anxiety, Behaviour, Temperament and Dental Caries in Children}

\author{
Emine Kaya*, Sinem Yıldırım \\ Department of Paediatric Dentistry, Faculty of Dentistry, İstanbul Okan \\ University, 34959 Tuzla, Istanbul, Turkey
}

^Corresponding author: eminetass@gmail.com

To cite this article: Kaya E, Y1ldirım S (2021). The relationship of dental anxiety, behaviour, temperament and dental caries in children. Arch Orofac Sci, 16(2): 103-112. https://doi.org/10.21315/ $\operatorname{aos} 2021.16 .2 .2$

To link to this article: https://doi.org/10.21315/aos2021.16.2.2

\begin{abstract}
The first dental examination is a major step that is affected by many factors and determines the dental treatment process. The main objective of this study was to evaluate the association of child temperament with child dental anxiety, parental dental anxiety, dental behaviour and dental caries. The study consisted of 100 children aged 3 to 6 who were attending their first dental examination and their accompanying parents. The Facial Image Scale (FIS), Frankl's Behaviour Scale (FBS), Corah's Dental Anxiety Scale (CDAS) and the Short Temperament Scale for Children (STSC) were used for assessment. The DMFT (decayed, missing and filled teeth) score of each child was recorded. Children who exhibited negative behaviour on the FBS had the highest rhythmicity scores $(p=0.008)$. The mean DMFT score of children in the rhythmicity temperamental dimension was relatively high $(p=0.008)$. The parents of children defined as negative on the FBS had high dental anxiety levels on CDAS $(p<0.001)$. Children whose parents had higher dental anxiety levels showed higher dental anxiety $(p=0.007)$. The success rate of dental treatment procedures may be increased by improving dentists' knowledge of dental anxiety related to the child's temperament and integrating parental support to reduce dental anxiety.
\end{abstract}

Keywords: Anxiety; behaviour; caries; child; temperament

\section{INTRODUCTION}

One of the most important public health challenges is dental caries, particularly among young children. Dental caries affects a child's quality of life by causing pain, complicating their ability to eat, sleep and learn, delaying physical development and restricting activities. To provide the appropriate dental treatment or preventive measures for caries in children are often difficult due to the fear and anxiety of children towards dentists (Balasubramanian et al., 2018). In addition, some studies have reported that children with severe dental caries and inadequate oral hygiene have higher dental anxiety (Taani et al., 2005; Klingberg \& Broberg, 2007).

Dental anxiety is described as abnormal fear or unwarranted apprehension of visiting the dentist for dental treatment procedures. Dental anxiety has been reported as a common phenomenon in paediatric patients, with an estimated prevalence between $6 \%$ and $20 \%$ due to the predominance of children's perceptual imagination over logical judgement (Jain et al., 2019). Various parameters, such as gender, age, parenting styles, cognitive level, reaction to strangers, 
social expectations and temperament, influence dental anxiety among children (Morgan et al., 2017; Jain et al., 2019). Parental dental anxiety is one of the indirect factors that play an important role in the dental anxiety of their children; parental attitudes can increase the severity of anxiety symptoms in children (Karibe et al., 2014). The dental anxiety of mothers may influence their attitudes and habits regarding the child's oral health care, especially the dental attendance pattern (Goettems et al., 2012).

Temperament in childhood is defined as an emotional essence of personality that varies individually with a strong genetic or neurobiological basis and refers to environmental interaction style. In child developmental psychology, temperament is a crucial concept remaining relatively stable across time and situations, but it can be modified by environmental effects or may vary with age and gender (ElseQuest et al., 2006). Temperament can be categorised into four types or tendencies: Reactivity, persistence, approach and rhythmicity (Yagmurlu \& Sanson, 2009a). Temperamental characteristics have a powerful influence on trait anxiety and the adaptive or maladaptive functioning of children. It has been reported that there is a direct relation between temperamental traits of children and dental anxiety (Dahlander et al., 2019). While some paediatric patients are able to cope well with their dental visits, others display some dental behaviour management problems associated with dental anxiety that cause delaying or cancellation of dental treatment (Talo Yildirim et al., 2017).

There are few studies in the literature on the correlation between dental anxiety and child temperament which stated that shyness and negative emotionality temperaments induce dental anxiety among paediatric patients (Klingberg \& Broberg, 1998; Stenebrand et al., 2013; Jain et al., 2019). A statistically significant correlation between dental anxiety and emotional or shy temperaments was also reported (Jain et al., 2019). While some studies have investigated separately the relationship between a child's temperament and dental anxiety (Klingberg \& Broberg, 1998; Stenebrand et al., 2013), the relationship between parental anxiety and the dental anxiety of children (Folayan et al., 2002; Kyritsi et al., 2009; Karibe et al., 2014), and the relationship between a child's temperament and their caries (Aminabadi et al., 2014), no study has examined the aforementioned factors taken together.

This study aimed to investigate the association of child temperament with child dental anxiety, parental dental anxiety, dental behaviour and dental caries. Based on the literature, three null hypotheses were considered. The first was that there is no association between the children's temperament and their anxiety. The second was that temperament would not correlate with dental caries and the third was that parental dental anxiety would not correlate with the dental anxiety of children.

\section{MATERIALS AND METHODS}

\section{Participants and Setting}

This cross-sectional study was conducted with 100 children and their accompanying parents who visited the Department of Paediatric Dentistry from November 2019 to June 2020 for their first dental visit. The following criteria were considered for inclusion in the study:

1. Three- to six-year-old paediatric patients.

2. Children having their first dental visit.

3. No known medical conditions limiting the cognitive development of the child.

4. No known communicative disorders or psychiatric diagnoses.

5. No diagnosed chronic medical conditions.

6. No history of pulpitis or tooth infection pain.

7. No history of an unpleasant medical experience. 
The study protocol was approved by the Institutional Ethics Committee (Ref. No. 2019/114). Informed consent was obtained from parents after explaining the purpose of the study. Based on data from a previous study (Jain et al., 2019), a minimum sample size of 100 subjects was determined via the $G^{\star}$ Power software programme (power $=0.80, \alpha=0.05, \beta=0.20, G^{\star}$ Power, v. 3.1.9.2). Children who met the inclusion criteria were randomly selected six months after ethical approval. Children who had no previous dental examination were included in this study in order to eliminate any possible dental anxiety due to previous dental experiences. The age range (3-6 years) of the children was chosen based on previous studies (Klaassen et al., 2007; Klingberg \& Broberg, 2007; Jain et al., 2019). The children were allowed to spend time in the playroom area to become comfortable in the dental clinic environment before their first oral examination. The examination was performed by the same operator in the presence of the parents. For the oral examination, only a dental mirror and a probe were used in accordance with the tellshow-do technique.

\section{Outcome Measures}

To measure the dental anxiety of the child, the Facial Image Scale (FIS) (Buchanan \& Niven, 2003) was used just after the oral examination. The FIS presents a row of five faces ranging from very happy to very unhappy. Each child was asked to choose a face that was most similar to his/her feeling at that moment. The DMFT (decayed, missing and filled teeth) score for primary teeth was calculated for each paediatric patient. Each child's sitting pattern (whether he/she climbed into the chair independently or was placed in the chair by a parent) (Yildirim et al., 2018) was recorded by the examining dentist.

The behaviour of children was assessed according to the Frankl Behaviour Scale (FBS) (Frankl et al., 1962). Another experienced paediatric dentist assessed the child's behaviour while commencing an oral examination. FBS divides observed behaviour into four categories, ranging from definitely positive to definitely negative, as follows:

1. Definitely negative: Immature and uncontrollable, refuses treatment, shows defiant behaviour and cries forcefully.

2. Negative: Reluctant to accept dental therapy; immature, whining and timid.

3. Positive: Accepts dental therapy, tense but cooperative, whining and timid.

4. Definitely positive: Good rapport, understanding and interested.

After dental examination, all parents were asked to fill out the Corah's Dental Anxiety Scale (CDAS) (Ilgüy et al., 2005) and the Short Temperament Scale for Children (STSC) (Yagmurlu \& Sanson, 2009b; Yagmurlu \& Altan, 2010) in the Turkish language. There was an additional section for parents to fill out with questions on sex, age, education level of parent and number of children. When both parents accompanied the child, the one who spends more time with the child was asked to fill out the survey. In the case of families with multiple children, only one child was chosen randomly for the study to help decrease bias.

To define the dental anxiety level of parents, the CDAS (Corah, 1969) was completed by the accompanying parent. The validity and reliability of the translation has been established in previously published research (Ilgüy et al., 2005; Seydaoğlu et al., 2006). The CDAS includes four items to measure dental anxiety on a five-point Likert-type scale. Each question is scored from one (not anxious) to five (extremely anxious). The lowest score obtained from the scale was 5 and the highest score was 20. The total dental anxiety score was classified into three groups: Low anxiety (score less than 13), moderate anxiety (scores 13-15) and high anxiety (greater than 15). 
The children's temperament was assessed by the STSC. The validity and reliability of the Turkish translation was established in previously published research (Yagmurlu \& Sanson, 2009b; Yagmurlu \& Altan, 2010). This version contains 30 items describing different characteristics of the child in which each behaviour is rated on a 6-point Likerttype scale from 1 (not at all like my child) to 6 (very much like my child), which was completed by a parent. The scale has four dimensions: reactivity, persistence (tendency to persevere with activities or tasks), approach (withdrawal from new people, situations), and rhythmicity (regularity and predictability of the child's biological and behavioural functions). A high score indicates relatively high reactivity and persistence but low approach and rhythmicity temperamental traits.

\section{Statistical Analysis}

Data analysis was performed with SPSS 14.0 (IBM Corp, Chicago, Illinois). Descriptive statistics of quantitative variables were shown as mean \pm standard deviation (SD) and median (Q1-Q3), while qualitative variables were presented as count and percentage. Normality of quantitative variables was evaluated with the Shapiro-Wilk test. For the normally distributed groups, comparisons were performed with a $t$-test or one-way analysis of variance (ANOVA). MannWhitney and Kruskal-Wallis tests were used for the comparison of non-normally distributed groups. Associations between quantitative variables were evaluated with Spearman correlation analysis. Chisquare analysis was conducted to assess the relationship between qualitative variables. $P$ values less than 0.05 were considered significant.

\section{RESULTS}

Of the 100 children who participated in the study, 54 were girls (mean age [SD] $4.94 \pm 0.11$ ) and 46 were boys (mean age [SD] 4.48 \pm 0.14$)$. The values of FBS, FIS and CDAS variables are presented in Table 1. Fifty-nine percent of the children showed definitely positive behaviour, $28 \%$ exhibited positive behaviour, nine showed negative behaviour and the remaining four exhibited definitely negative behaviour on the FBS. Nine percent of the children exhibited high dental anxiety on the FIS, while $50 \%$ showed low dental anxiety. Boys exhibited higher dental anxiety than girls, according to the FIS. Among all participants, 73 parents exhibited low dental anxiety, 16 parents exhibited moderate dental anxiety and 11 parents exhibited high dental anxiety, according to the CDAS.

Table 1 Descriptive statistics

\begin{tabular}{|c|c|c|c|c|c|}
\hline Variable & $n$ & Mean \pm SD & SD & Median (Q1-Q3) & Max. score \\
\hline Age & 100 & $4.73 \pm 0.03$ & 0.91 & $5(4-5)$ & 6.00 \\
\hline FBS & 100 & $3.42 \pm 0.26$ & 0.82 & $4(3-4)$ & 4.00 \\
\hline FIS & 100 & $2.02 \pm 0.42$ & 1.33 & $1.5(1-2.75)$ & 5.00 \\
\hline CDAS & 100 & $10.09 \pm 1.21$ & 3.84 & $10(7-13)$ & 18.00 \\
\hline STSC/reactivity & 100 & $4.04 \pm 0.26$ & 0.82 & $4(3.55-4.66)$ & 5.77 \\
\hline STSC/persistent & 100 & $3.20 \pm 0.27$ & 0.86 & $3.14(2.43-3.82)$ & 5.00 \\
\hline STSC/approach & 100 & $3.17 \pm 0.30$ & 0.96 & $3.07(2.42-3.85)$ & 5.42 \\
\hline STSC/rhythmicity & 100 & $2.98 \pm 0.23$ & 0.74 & $3(2.42-3.42)$ & 4.71 \\
\hline DMFT & 100 & $4.18 \pm 1.35$ & 4.27 & $3(0-8)$ & 16.00 \\
\hline
\end{tabular}


Table 2 The correlation coefficient between temperament, dental anxiety, dental behaviour and parental anxiety

\begin{tabular}{lccccc} 
Scales & & STSC/reactivity & STSC/persistent & STSC/approach & STSC/rhythmicity \\
FIS & $r_{s}$ & -0.138 & 0.062 & 0.169 & 0.049 \\
& $p$ & 0.172 & 0.537 & 0.094 & 0.631 \\
CDAS & $r_{s}$ & 0.001 & 0.087 & 0.022 & 0.045 \\
& $p$ & 0.990 & 0.389 & 0.824 & 0.657 \\
FBS & $r_{s}$ & 0.021 & 0.047 & 0.101 & 0.097 \\
& $p$ & 0.840 & 0.641 & 0.318 & 0.338 \\
\hline
\end{tabular}

Table 3 The association between temperamental dimensions and FBS

\begin{tabular}{|c|c|c|c|c|c|c|c|c|c|}
\hline \multirow{2}{*}{ STSC subscales } & \multicolumn{2}{|c|}{ Definitely negative } & \multicolumn{2}{|c|}{ Negative } & \multicolumn{2}{|c|}{ Positive } & \multicolumn{2}{|c|}{ Definitely positive } & \multirow{2}{*}{$p$} \\
\hline & $n$ & Mean \pm SD & $n$ & Mean \pm SD & $n$ & Mean \pm SD & $n$ & Mean \pm SD & \\
\hline STSC/reactivity & 4 & $4.27 \pm 1.08$ & 9 & $3.88 \pm 0.60$ & 28 & $4.03 \pm 0.51$ & 59 & $4.05 \pm 0.35$ & 0.884 \\
\hline STSC/persistent & 4 & $3.00 \pm 2.56$ & 9 & $3.33 \pm 0.89$ & 28 & $3.11 \pm 0.54$ & 59 & $3.23 \pm 0.32$ & 0.847 \\
\hline STSC/approach & 4 & $2.92 \pm 1.64$ & 9 & $3.23 \pm 1.11$ & 28 & $3.06 \pm 0.60$ & 59 & $3.23 \pm 0.38$ & 0.834 \\
\hline STSC/rhythmicity & 4 & $3.28 \pm 0.95^{\mathrm{ab}}$ & 9 & $3.35 \pm 0.41^{b}$ & 28 & $2.59 \pm 0.38^{a}$ & 59 & $3.08 \pm 0.32^{b}$ & 0.008 \\
\hline
\end{tabular}

Note: Groups that do not share a common letter are significantly different.

Table 4 Spearman's correlation coefficients between age and other parameters

\begin{tabular}{lccccccccc} 
Variable & DMFT & FBS & FIS & CDAS & Reactivity & Persistent & Approach & Rhythmicity \\
Age & $r_{s}$ & 0.215 & 0.398 & -0.230 & -0.215 & -0.095 & 0.094 & 0.245 & 0.300 \\
& $p$ & 0.031 & $<0.001$ & 0.021 & 0.031 & 0.346 & 0.353 & 0.014 & 0.002 \\
\hline
\end{tabular}

The correlation values between temperamental dimensions with FIS and CDAS are presented in Table 2. There was no significant correlation between temperament and FIS or CDAS. The correlation values between temperamental and FBS categories are presented in Table 3. The children who exhibited negative behaviour on FBS had the highest rhythmicity scores $(p=0.008)$. The mean DMFT score for children who were in the rhythmicity temperamental dimension was relatively high (0.008). There was no significant correlation between DMFT and CDAS and FBS. The correlation values between age and DMFT, FIS, CDAS, and FBS values are shown in Table 4. There was a weak but significant relation between approach $(p=0.014)$ and rhythmicity $(p=0.002)$ temperamental dimensions and age.
Table 5 Spearman's correlation coefficients among FBS, FIS and CDAS

\begin{tabular}{|c|c|c|c|}
\hline Scales & & FIS & CDAS \\
\hline \multirow[t]{3}{*}{ FBS } & & -0.294 & -0.424 \\
\hline & & 0.003 & $<0.001$ \\
\hline & & CDAS & \\
\hline \multirow[t]{2}{*}{ FIS } & $r_{s}$ & 0.266 & \\
\hline & $p$ & 0.007 & \\
\hline
\end{tabular}

There was a significant difference between FBS scores and sitting patterns $(p<0.001)$. The children who exhibited definitely positive or positive behaviour sat independently on the dental chair: $94 \%$ of the children sat independently and $6 \%$ were seated by their parents on the dental chair. There was a weak but meaningful relationship between FBS and FIS variables 
$(r=0.294, p=0.003)$. Parents whose children were rated as negative on FBS had high dental anxiety levels on CDAS $(p<0.001)$. There was a positive, weak, but statistically significant relationship between FIS and CDAS $(r=0.266, p=0.007)$ (Table 5).

Regarding the education level of parents, those of 33 children had a low educational level, while 67 parents had a high level of education. Children whose parents were in the low education level group showed high FBS scores, and this was statistically significant $(p<0.001)$. Children whose parents were in the low education level group exhibited high persistence (0.01) and low rhythmicity $(p<0.001)$ temperamental traits. The mean DMFT score for children whose parents had less education was significantly high $(p=0.002)$.

\section{DISCUSSION}

In the present study, the impact of temperament characteristics of children on dental anxiety, dental behaviour and DMFT were evaluated. According to the results, the first null hypothesis of the study was accepted: no significant differences were found between temperamental dimensions and FIS and FBS. Since the mean DMFT score for children who were in the rhythmicity temperamental dimension was relatively high, the second null hypothesis was partially rejected. In addition, a weak positive correlation was found between FIS and CDAS. For this reason, the third null hypothesis was rejected.

Childhood temperament features have been determined to be a valuable predictor of how a child will react to a variety of potentially stressful situations (Kagan et al., 1987). The first dental visit can be a stressful situation for children and plays a pivotal role in the development of their attitudes in relation to dental anxiety. According to the results, although there was no significant correlation between dental anxiety, dental behaviour and temperament, the reactivity subscale of the STSC score of those who had definitely negative attitudes according to FBS was the highest. Reactivity or negative emotionality has an important effect on children's behavioural problems (Rubin et al., 1995). High levels of children's negative emotions cause more intense responses and greater difficulties in interpersonal relations. Moreover, highly reactive children are prone to feeling anger and are less competent in self-regulation. This is in line with the results of a previous study assessing the correlation between child temperament and behaviour in relation to age in the dental setting (Aminabadi et al., 2011). The study reported a significant negative correlation between the child's behaviour and temperament dimensions of reactivity, shyness, anger, irritability and fear, indicating that more negative temperaments exhibit more negative behaviour.

Previous studies have found that shyness and emotionality can contribute to the development of dental anxiety in children (Klingberg \& Broberg, 1998; Jain et al., 2019). The present study demonstrated a slightly different result that may arise from the diversity of the studied populations, considering differences in cultural aspects. An additional reason for the discrepancy may be related to the quite low number of children who exhibited negative behaviour on FBS and a high level of dental anxiety according to FIS. It should also be taken into consideration that the scales used in those studies were different from those used in our study.

The present study found a positive, weak, but significant relationship between DMFT values and temperamental features of rhythmicity. This finding indicates that children with high DMFT values were unregulated and had unpredictable biological functions. This result was in accordance with a previous study which reported that children with early childhood caries (ECC) were found to be less rhythmic than children without ECC (Jabin \& Chaudhary, 2014). 
Similarly, another study reported positive temperaments were higher in the cariesfree group and negative temperaments were higher in the ECC group (Aminabadi et al., 2014). Poor modulation of regular tooth brushing habits and eating patterns can be defined as rhythmicity problems. Both irregular oral hygiene and dietary habits might cause an increase in the prevalence of dental caries in children.

Taani et al. (2005) reported that there was no obvious association between dental anxiety and dental caries or gingivitis in children. Similarly, this study demonstrated no significant correlation between FBS, FIS, CDAS and DMFT scores. On the other hand, our findings were contrary to the studies in which a significant association was observed between caries and dental anxiety (Kruger et al., 1998; Rantavuori et al., 2004). A probable explanation for this discrepancy may be that the number of children with high dental anxiety was considerably lower than those with low dental anxiety.

There is no consensus on the relationship between the dental anxiety of children and parental dental anxiety. Alwin et al. (1991) reported a weak relationship between the dental anxiety of children and that of their parents, so children may not have learned dental anxiety from their families. However, some studies have stated that the dental anxiety of parents negatively affects the behaviour of children during dental treatment (Folayan et al., 2002; Rantavuori et al., 2004; Klingberg \& Broberg, 2007). Similarly, in this study, it was observed that parental dental anxiety levels increased the dental anxiety level of children.

To identify children's dental anxiety during their first dental visit, various scales, such as records of the patient's self-reported anxiety status, clinician rating of dental behaviour and family evaluation, were used in the present study. We aimed to overcome the inaccuracies and limitations of each method to allow a broader approach. In line with previous research (Kyritsi et al., 2009;
Salem et al., 2012), a significant association was found between FIS, CDAS and dental behaviour. The verbal skills of the children in this age group are often quite limited; therefore, we used the FIS, which is based on facial images and has proven to be a valid instrument in many studies (Buchanan \& Niven, 2002; Cantekin et al., 2014).

Dental anxiety is a multi-factorial and complex notion that is affected by several variables. Dental anxiety levels may be influenced by the gender, age and education level of parents. In the present study, the dental anxiety level of boys was higher than that of girls, which was in contrast with previous studies (Klingberg \& Broberg, 1998; Jain et al., 2019). A significant negative correlation was observed between age and FIS. In other words, the dental anxiety levels of children decreased with increasing age. These results are in line with the study of Mishra et al. (2016), which stated that increasing age is directly related to a child's dental anxiety. Additionally, Camilleri et al. (2004) stated that children younger than three years of age lack cooperation and communication abilities, but these skills improve with increasing age. After the age of six, children acquire adjustment, independence and self-control abilities and can be expected to show few behavioural management problems during dental treatment (Camilleri et al., 2004). Similarly, Jain et al. (2019) studied the association of temperament with dental anxiety and the behaviour of preschool children aged three to five during their initial dental visit. Based on the aforementioned information, three- to six-year-old children who were visiting the dental clinic for the first time were selected for the current study.

Although temperament influences dental anxiety and caries, it cannot be derived from the results of the present study. These results may be explained by the relatively low sample size of the high dental anxiety group. Child temperament evaluation in this study was carried out by parental ratings, which may be influenced by the education level of parents, 
socio-economic status and parental stress. The limitations of the present study mentioned above should be taken into consideration when interpreting our results. Future studies should be carried out on children with different dental anxiety levels and in different age groups to investigate other factors, such as unpleasant previous dental experiences and parenting styles. Paediatric dentists should encourage children to improve their oral hygiene habits in accordance with their temperaments.

\section{CONCLUSION}

According to the results of the present study, no significant association between temperament and dental anxiety of children was found. Children who exhibited definitely negative attitudes according to FBS had the highest reactivity temperamental scores. A positive relationship between DMFT values and temperamental feature of rhythmicity was observed. A positive correlation between parental dental anxiety and children's dental anxiety was found.

\section{REFERENCES}

Alwin NP, Murray JJ, Britton PG (1991). An assessment of dental anxiety in children. Br Dent F, 171(7): 201-207. https://doi.org/ 10.1038/sj.bdj.4807661

Aminabadi NA, Ghoreishizadeh A, Ghoreishizadeh M, Oskouei SG, Ghojazadeh M (2014). Can child temperament be related to early childhood caries? Caries Res, 48(1): 3-12. https://doi .org/10.1159/000351636

Aminabadi NA, Puralibaba F, Erfanparast L, Najafpour E, Jamali Z, Adhami SE (2011). Impact of temperament on child behavior in the dental setting. $f$ Dent Res Dent Clin Dent Prospects, 5(4): 119-122. https://doi .org/10.5681/joddd.2011.027
Balasubramanian S, Shrikrishna SB, Shenoy R, Rao A (2018). Association of maternal and child dental anxiety with dental caries experience and dental attendance pattern of the child. f Orofac Sci, 10(2): 75-79. https://doi.org/10.4103/jofs.jofs_7_18

Buchanan H, Niven N (2002). Validation of a facial image scale to assess child dental anxiety. Int $\mathcal{F}$ Paediatr Dent, 12(1): 47-52.

Buchanan H, Niven N (2003). Further evidence for the validity of the Facial Image Scale. Int $\mathcal{f}$ Paediatr Dent, 13(5): 368-369. https://doi.org/10.1046/j.1365-263X.2003 $.00488 . x$

Camilleri A, Roberts G, Ashley P, Scheer B (2004). Analysis of paediatric dental care provided under general anaesthesia and levels of dental disease in two hospitals. Br Dent F, 196(4): 219-223. https://doi.org/ 10.1038/sj.bdj.4810988

Cantekin K, Yildirim MD, Delikan E, Cetin S (2014). Postoperative discomfort of dental rehabilitation under general anesthesia. Pak f Med Sci, 30(4): 784-788. https://doi .org/10.12669/pims.304.4807

Corah NL (1969). Development of a dental anxiety scale. $\mathcal{f}$ Dent Res, 48(4): 596. https://doi.org/10.1177/002203456904800 41801

Dahlander A, Soares F, Grindefjord M, Dahllöf G (2019). Factors associated with dental fear and anxiety in children aged 7 to 9 years. Dent $\mathcal{F}$ (Basel), 7(3): 68. https://doi .org/10.3390/dj7030068

Else-Quest NM, Hyde JS, Goldsmith HH, Van Hulle CA (2006). Gender differences in temperament: A meta-analysis. Psychol Bull, 132(1): 33-72. https://doi.org/10.1037/ 0033-2909.132.1.33 
Folayan MO, Adekoya-Sofowora CA, D Otuyemi O, Ufomata D (2002). Parental anxiety as a possible predisposing factor to child dental anxiety in patients seen in a suburban dental hospital in Nigeria. Int $\mathcal{f}$ Paediatr Dent, 12(4): 255-259. https://doi.org/10.1046/j.1365-263x.2002 $.00367 . x$

Frankl SN, Shiere FR, Fogels HR (1962). Should the parent remain with the child in the dental operatory? f Dent Child, 29: 150163.

Goettems ML, Ardenghi TM, Demarco FF, Romano AR, Torriani DD (2012). Children's use of dental services: Influence of maternal dental anxiety, attendance pattern, and perception of children's quality of life. Community Dent Oral Epidemiol, 40(5): 451-458. https://doi.org/ 10.1111/j.1600-0528.2012.00694.x

Ilgüy D, Ilgüy M, Dinçer S, Bayirli G (2005). Reliability and validity of the modified dental anxiety scale in Turkish patients. f Int Med Res, 33(2): 252-259. https://doi .org/10.1177/147323000503300214

Jabin Z, Chaudhary S (2014). Association of child temperament with early childhood caries. I Clin Diagn Res, 8(12): ZC21ZC24. https://doi.org/10.7860/JCDR/2014/ 9770.5262

Jain A, Suprabha BS, Shenoy R, Rao A (2019). Association of temperament with dental anxiety and behaviour of the preschool child during the initial dental visit. Eur f Oral Sci, 127(2): 147-155. https://doi. org/10.1111/eos.12606

Kagan J, Reznick JS, Snidman N (1987). The physiology and psychology of behavioral inhibition in children. Child Dev, 58(6): 1459-1473.

Karibe H, Aoyagi-Naka K, Koda A (2014). Maternal anxiety and child fear during dental procedures: A preliminary study. f Dent Child (Chic), 81(2): 72-77.
Klaassen MA, Veerkamp JS, Hoogstraten J (2007). Dental fear, communication and behavioural management problems in children referred for dental problems. Int $f$ Paediatr Dent, 17(6): 469-477. https://doi.org/10.1111/j.1365-263X.2007 $.00870 . \mathrm{x}$

Klingberg G, Broberg AG (1998). Temperament and child dental fear. Pediatr Dent, 20(4): 237-243.

Klingberg G, Broberg AG (2007). Dental fear/ anxiety and dental behaviour management problems in children and adolescents: A review of prevalence and concomitant psychological factors. Int $\mathcal{F}$ Paediatr Dent, 17(6): 391-406. https://doi.org/10.1111/ j.1365-263X.2007.00872.x

Kruger E, Thomson WM, Poulton R, Davies S, Brown RH, Silva PA (1998). Dental caries and changes in dental anxiety in late adolescence. Community Dent Oral Epidemiol, 26(5): 355-359. https://doi.org/ 10.1111/j.1600-0528.1998.tb01973.x

Kyritsi MA, Dimou G, Lygidakis NA (2009). Parental attitudes and perceptions affecting children's dental behaviour in Greek population. A clinical study. Eur Arch Paediatr Dent, 10(1): 29-32. https://doi.org/ 10.1007/BF03262664

Mishra G, Thakur S, Singhal P, Ghosh SN, Chauhan D, Jayam C (2016). Assessment of child behavior in dental operatory in relation to sociodemographic factors, general anxiety, body mass index and role of multimedia distraction. F Indian Soc Pedod Prev Dent, 34(2): 159-164. https://doi.org/10.4103/0970-4388.180446

Morgan AG, Rodd HD, Porritt JM, Baker SR, Creswell C, Newton $\mathrm{T}$ et al. (2017). Children's experiences of dental anxiety. Int $\mathcal{f}$ Paediatr Dent, 27(2): 87-97. https://doi.org/10.1111/ipd.12238 
Rantavuori K, Lahti S, Hausen H, Seppä L, Kärkkäinen S (2004). Dental fear and oral health and family characteristics of Finnish children. Acta Odontol Scand, 62(4): 207-213. https://doi.org/ $10.1080 / 00016350410001586$

Rubin KH, Coplan RJ, Fox NA, Calkins SD (1995). Emotionality, emotion regulation, and preschoolers' social adaptation. Dev Psychopathol, 7(1): 49-62. https://doi.org/ 10.1017/S0954579400006337

Salem K, Kousha M, Anissian A, Shahabi A (2012). Dental fear and concomitant factors in 3-6 year-old children. $\mathcal{F}$ Dent Res Dent Clin Dent Prospects, 6(2): 70-74. https://doi.org/10.5681/joddd.2012.015

Seydaoğlu G, Doğan MC, Uğuz S, Inanç BY, Çelik M (2006). Reliability and validity of the Turkish version of the Corah dental anxiety scale and the frequency of dental anxiety. Ondokuz Mayis Univ Dis Hekim Fak Derg, 7(1): 7-14.

Stenebrand A, Wide Boman U, Hakeberg M (2013). Dental anxiety and temperament in 15-year olds. Acta Odontol Scand, 71(1): 15-21. https://doi.org/10.3109/00016357 .2011 .645068

Taani DQ, El-Qaderi SS, Abu Alhaija ES (2005). Dental anxiety in children and its relationship to dental caries and gingival condition. Int $\mathcal{F}$ Dent Hyg, 3(2): 83-87. https://doi.org/10.1111/j.1601-5037.2005 $.00127 . \mathrm{x}$
Talo Yildirim T, Dundar S, Bozoglan A, Karaman T, Dildes N, Acun Kaya F et al. (2017). Is there a relation between dental anxiety, fear and general psychological status? Peerf, 5: e2978. https://doi.org/ $10.7717 /$ peerj. 2978

Yagmurlu B, Altan O (2010). Maternal socialization and child temperament as predictors of emotion regulation in Turkish preschoolers. Infant Child Dev, 19(3): 275296. https://doi.org//10.1002/icd.646

Yagmurlu B, Sanson A (2009a). Acculturation and parenting among Turkish mothers in Australia. $\mathcal{F}$ Cross-Cult Psychol, 40(3): 361-380. https://doi.org/10.1177/00220 22109332671

Yagmurlu B, Sanson A (2009b). Parenting and temperament as predictors of prosocial behaviour in Australian and Turkish Australian children. Aust $\mathcal{f}$ Psychol, 61(2): 77-88. https://doi.org/10 $.1080 / 00049530802001338$

Yildırım S, Bakkal M, Bulut H, Selek S (2018). Quantitative evaluation of dental anxiety indicators in the serum and saliva samples of children treated under general anesthesia. Clin Oral Investig, 22(6): 23732380. https://doi.org/10.1007/s00784-018 $-2340-2$ 